\title{
VIEWPOINT
}

\section{Urban Questions in the Times of Coronavirus. Responding to the Crisis of Public Space}

Darko Radović (Keio University, co+re), Davisi Boontharm (Meiji University, co+re) radovic@keio.jp | nout.davisi@gmail.com

Antonella Bruzzese (Politecnico di Milano), Stephen Cairns (ETH Future Cities Laboratory, Singapore), Alenka Fikfak (University of Ljubljana), Pieter Klomp (City of Amsterdam), Kengo Kuma (KKAA, University of Tokyo), Beatriz Maturana Cossio (Universidad de Chile), Ana Medina (Universidad des las Américas), Eiji Oguma (Keio University, Tokyo) David Sim (Gehl, Copenhagen), Sidh Sintusingha (University of Melbourne), Saline Verhoeven (s-coop, Amsterdam)

\begin{abstract}
This paper is co-edited on the basis of an intensive round-table discussions within a relatively small group of colleagues interested and involved in thinking, making and working towards quality of public space, to discuss, problematise and evaluate what is going on and to speculate on actions suitable for these times, and the times that follow. The title of the round table emphasises questions, deliberately pointing at the enigmas posed by current situation. We see it as an opportunity to get and think together in a structured brain-storming session that encourages brave and risky discussion. The "task" for all of the participants is to reflect upon practices/experiences that we are individually familiar with, those that we are witnessing these days, and - to suggest what would be the key questions /issues that need to be (re)thought and addressed in the weeks, months, perhaps years to come. The roundtable discussions were held online on Ist May 2020 - then recorded, transcribed, edited and published as a joint piece.
\end{abstract}

Keywords: public space, COVID-19, immediate response, cross-cultural perspectives

To cite this article:

Radović, D., Boontharm, D., Bruzzese, A. Cairns, S., Fikfak, A., Klomp, P., Kuma, K., Cossio, B. M., Medina, A., Oguma, E., Sim, D., Sintusingha, S., Verhoeven, S. (2020). Urban Questions in the Times of Coronavirus. Responding to the Crisis of Public Space. The Journal of Public Space, 5(2), 233-248, DOI 10.3289I/jps.v5i3.I362

This article has been double blind peer reviewed and accepted for publication in The Journal of Public Space.

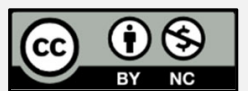

This work is licensed under a Creative Commons Attribution - Non Commercial 4.0 International License https://creativecommons.org/licenses/by-nc/4.0/ 


\section{Introduction}

The outbreak of Coronavirus provided us all with a surprise, a sort of shock and a sense of the need to react. But, not knowing much about the threat is not an easy place to begin. I remember initial distrust into reports, denial and rejection of "overreaction", mingling with completely opposite feelings of dismay, unease and the outright fear. Personal coincidences matter. Caught traveling we were first-hand experiencing the diversity of responses to the same cause. Our journey was never to be easy. It led us from Tokyo to Bangkok, then Belgrade, Zagreb to Ljubljana. Just before continuing to Milano, the borders started to close and we have (in hindsight - luckily) found ourselves in Split. Our flights back started to be rescheduled and postponed; the lock-down begun. There was a plenty of time to observe and reflect, firmly landed while, perhaps, globally connected more than ever.

For the first time in more than fifty years of knowing the city of Split, the magnificent Diocletian Palace and the fine-grained fabric of its public spaces were empty. The photos in the media and, even more dramatically, those coming from the people we knew were placing the sense of distress where our professional, academic and personal histories intersect - our love of the urban. Riva, the buzzing seafront of Split - empty. Diocletian's Peristyle - empty. Is an empty piazza still a piazza? Can we exercise our innate right to the city under the condition of the lock-down, in fear? This place, and some other places dear to me have experienced terrible natural and man-made disasters before. But, how to live this one, how to address its ills, how and what to do to reduce both the tragedy of the moment and help avoid similar tragedies in the future? Questions, questions, questions.

Staying in touch with dear ones, friends and colleagues included discussions of pressing questions: how to react, what to expect, how to do something about it. That is where the creative instincts and our background in disciplines related to the production of space kicked in. Planning and design are always about making a better world.

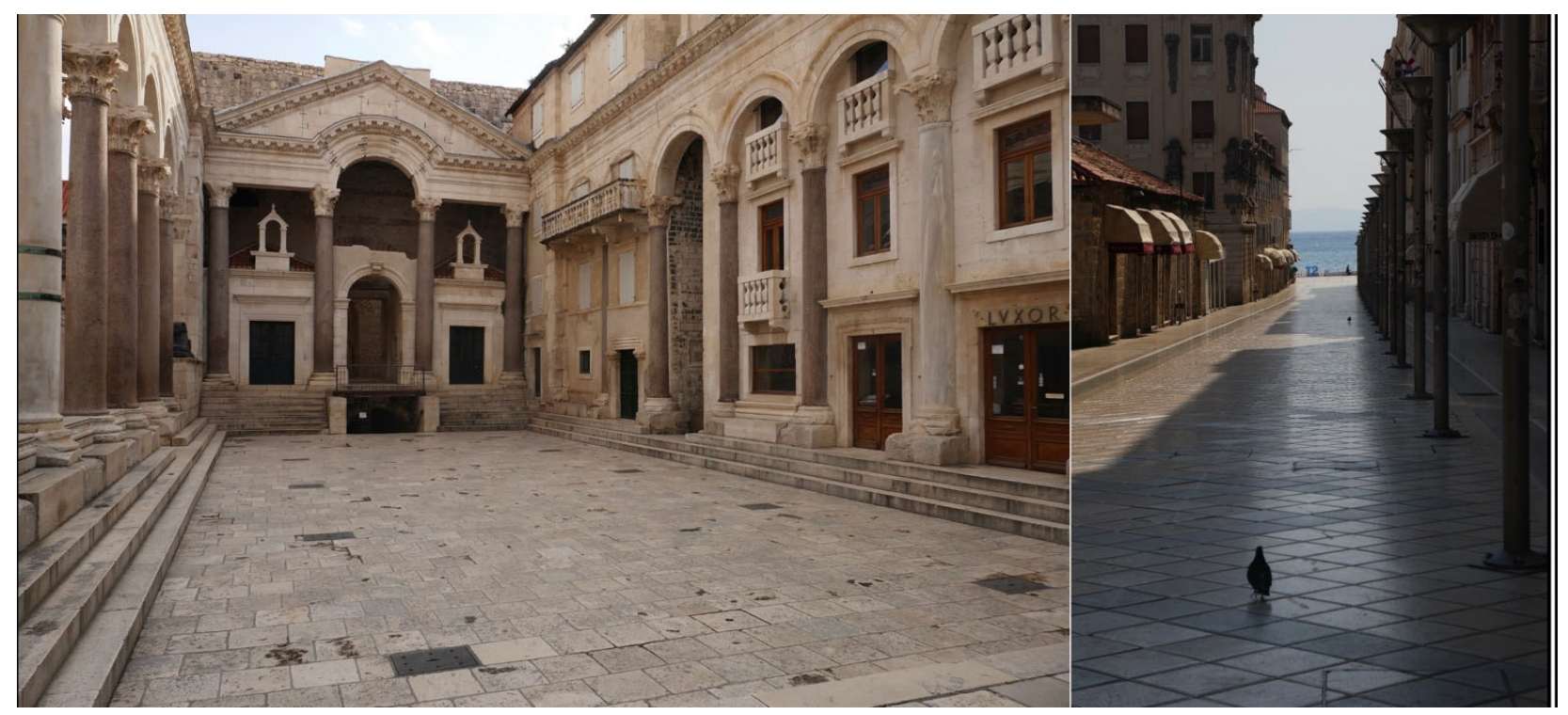

Figure I. Empty public spaces in Split, left: the Peristyle, right: Marmontova Street 


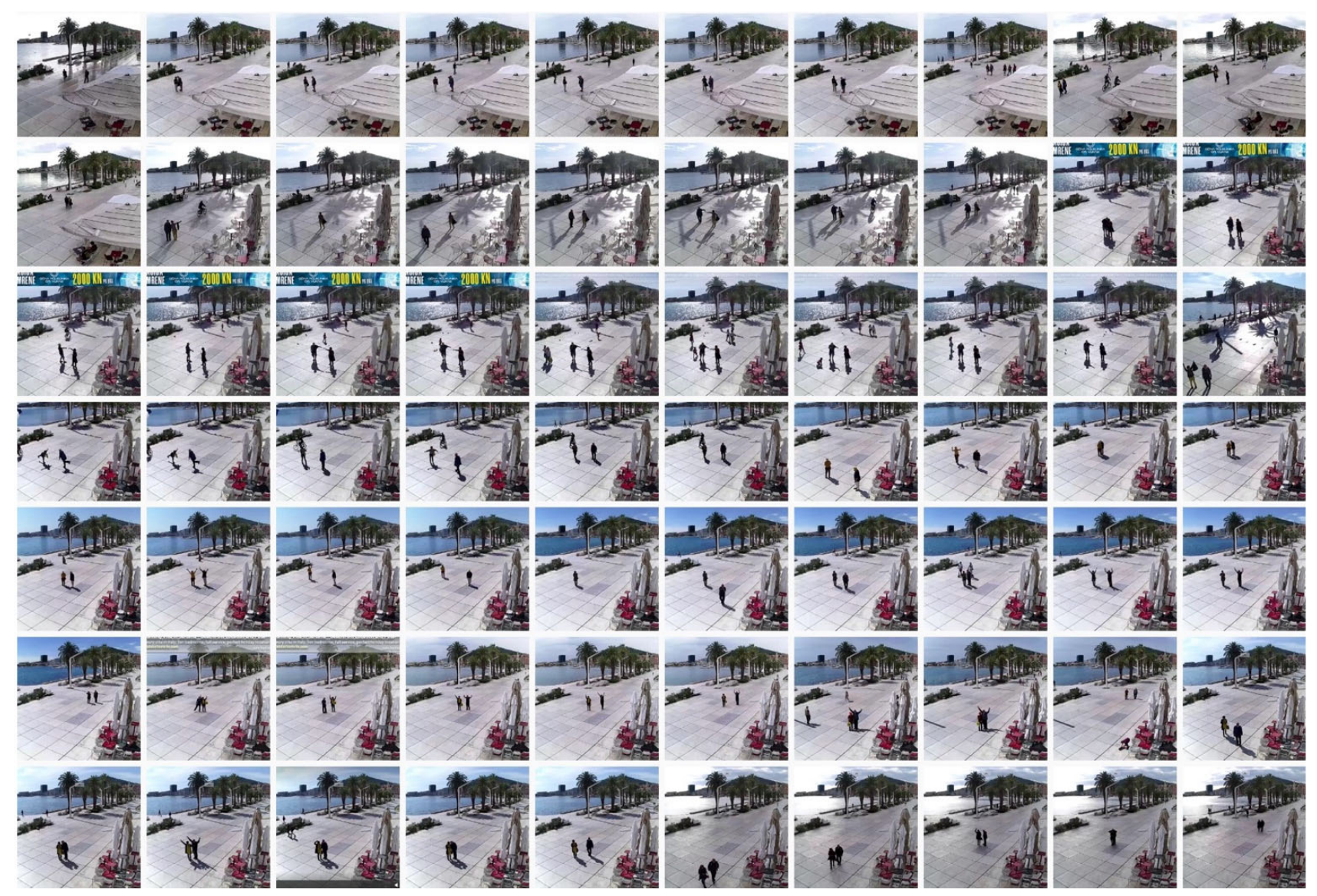

Figure 2. The compilation of snapshots taken from Split's Webcam on Riva during the lockdown

Darko as Senior co-Chair on the Advisory Board of Public Space Experts and Davisi as a Member of the Council Board, we have responded to the City Space Architecture "2020: A Year without Public Space under the COVID-I9 Pandemic" initiative by proposing a concrete action. Our emphasis was on the imperative to pause and formulate relevant questions. From day one of the pandemic the common rush for "solutions" has started, but we have found overarching, "simple" questions - such as solutions to what?! - sorely missing. Our times made us prone to almost religious belief in never-easier tech and financial fix to - everything. Many, at least in the (over)developed world, increasingly believe that, as Morozov has cynically, brilliantly put it, when things go wrong we simply can, "in order to save everything, click here". Unfortunately, the Coronavirus pandemic cannot be reversed by new app, or pressing the almighty Ctrl. $Z$ command. Serious situations demand serious thinking, measures which can reach beyond cheap (albeit usually financially expensive) fix. We have agreed that the Coronavirus pandemic invites humility. It points at our limitations and the need for different kind of thinking and action - with an acute sense of emergency.

On 15 April 2020, at City, Space, Architecture meeting we have agreed to place our proposal within the network of other worthy initiatives. On 17 April we invited a remarkable group of friends and colleagues across four continents, asking them to participate in discussion "Urban questions in the times of Coronavirus". All of them responded positively. On 25 April I only needed to explain the format. We would organise an intensive round-table discussion. The expectation from the strong panel 
interested and involved in thinking, making and working towards quality of public space, was to discuss, problematise and evaluate what was going on, and to speculate on actions suitable for these times, and the times that follow.

The title of the round table emphasised questions, pointing at the dilemmas and enigmas posed by the current situation. I saw it as an opportunity to think together in a structured brain-storming session that encourages brave and risky discussion. Each of the participants provided an opening, 250-500 words long input, with key observations, personal position, thoughts, questions and provocations that would move us faster. On I May we co-chaired two round tables

This unusual, co-produced, collective essay, which is aimed to open rather than close discussions, is the result of that initiative.

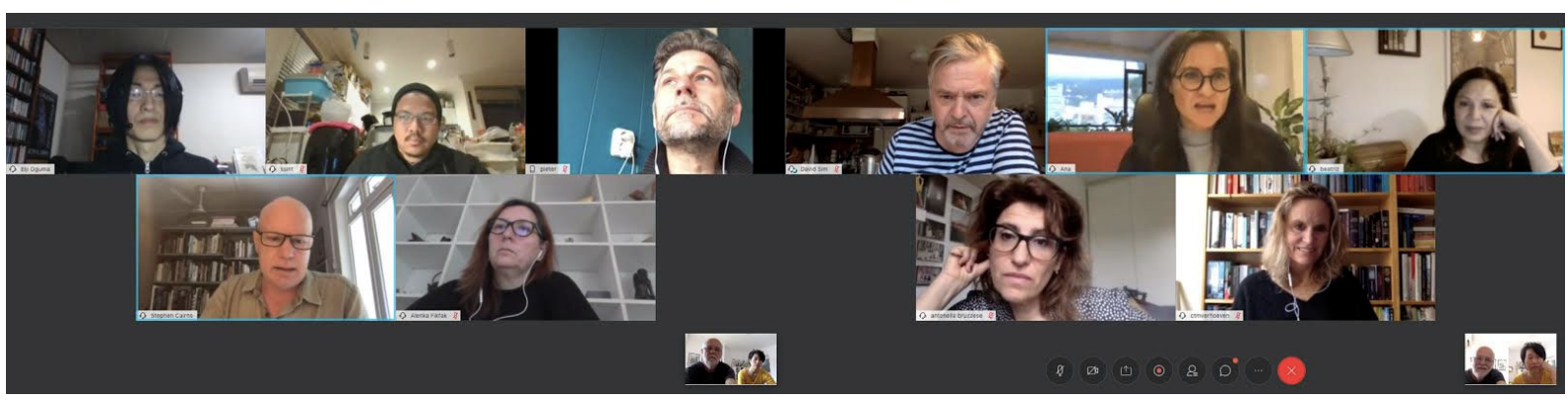

Figure 3. The participants of the two round tables (screenshots of the Webex meetings)

Roundtable session I, I May 2020

Davisi Boontharm DB, Stephen Cairns SC, Eiji Oguma EO, Alenka Fikfak AF, Pieter Klomp PK,

Kengo Kuma KK (inputs only), Sidh Sintusingha SS, Darko Radović DR, chair

\section{INPUTS}

KK: The theme I want to introduce could be called - the departure from the box. In the 20th century, we were trapped in boxes, boxes as workplaces and transportation machines. The city became filled up with boxes and in between were only the gaps to move. The century was called the "Century of Freedom", but being trapped in boxes seems very far from that ideal. Work in boxes enforced many sacrifices, especially on women. The Coronavirus crisis came in suddenly. The governments requested us to stay away from those boxes, except when expressly needed. The technology has proven that it was possible to work efficiently without such, inhuman confinement.

Breaking out of the box is also breaking out of the room. These days I walk a lot. By walking, my physical condition improved and, while walking, I have thought and sketched various things. I was able to choose distance from other people, which was not the case in steel, transportation boxes. Walking allows us to choose, to be alone and free. Being stuck in boxes became fully possible only with the advent of devilish air-conditioning machines. But the parks are not air-conditioned.

On the famous Giambattista Nolli's map of Rome (1748) all spaces accessible to anyone were white, regardless if external or interior; the publicly inaccessible spaces, such as private residences, were black. With invention of air-conditioners, the interiors became 
hermetically sealed, and the outside temperature has increased. The cars made the outdoors even more uncomfortable. The streets, supposed to be white on Nolli's map, become increasingly black and dirty. I felt that there was almost no white space in Tokyo. We need more white space and more human interaction.

In Hidden Dimension, Edward T. Hall points out the importance of cultural difference in perception of distances. Japanese gardens, with their steppingstones and narrow spaces, stimulate full use of muscles. Hall praises differentiation of places and distances. When exploring spaces by walking, one develops a fine sense of own body. Walking requires muscles to participate in the space. In the National Stadium, which I was involved in designing, we did not want to seal the roof off. We have proposed an open-air stadium that breathes together with the Gaien's Forest. The eaves were made of four layers allowing a wooden, airy stadium to be linked to the forest by garden design methods. Wood was not one of the building materials, but plants also cover the middle eaves. After the pandemic, I would like to keep on walking between the boxes and working while walking. With more of us walking, the gaps between the boxes will get transformed from empty voids into fully open, white places and ventilated gardens of human interaction.

SC: Epidemiologists have argued that urban density is one of the mediums that spread COVID. On the other side of the agenda, agencies interested in urban development from planning authorities to the World Bank - have been trying to show that the relationship between density and the COVID spread is not determining. Some indicators show the correlation, while others do not. In Singapore density is a nationally significant issue. Singapore has a deep commitment to the values of urban density. And, the citystate has been doing well in managing Covid-19 until it spread into the migrant dormitories and compounds. Suddenly, it seemed, two densities were revealed in the city: the density of a well-planned city and the density of migrant workers. This has quickly become an important topic of debate and will likely bring about policy and design reforms on managing density.

While there is so much ambiguity around the issue of density and COVID-19, we can venture a number of early practical trajectories. (I) we have to consider density in relation with all other aspects of cities; density can never just be a stand-alone quantitative indicator; (2) as COVID cases were mostly contracted indoors, we need to focus at making a well aerated city that makes good use of outdoors. A lot of interesting local examples already exist in Singapore, such as hawker centres (3) it is important to diversify mobility, with autonomous vehicles and electric vehicles breaking up a monolithic mass transportation system, particularly busses and their rigid schedules; and (4) designing a cyber-physical city in which we make better use of augmented and virtual realities in everyday spaces.

AF: I am coming from Slovenia, a small country with very low density of population, from the town of Vrhnika, which is situated $20 \mathrm{~km}$ from Ljubljana and has just 8,000 inhabitants. In these times the municipality borders were closed, there is no public transport, no possibility to go to Ljubljana. In terms of Coronavirus cases, with only 91 deaths, in Ljubljana region we did not have serious problems. In other municipalities the outbreaks were mainly in the homes for elderly. Municipalities bordering with Italy have no cases. That is because "stay at home" campaign starter early, on I 3 March. The 
streets were emptied, social distancing imposed, with only food stores and pharmacies open. The only public spaces used were urban gardens.

I wonder if these two months caused enough suffering to keep these rules seriously applied. The main questions which this outbreak leaves are cultural and social. As we are part of the Balkans, we tend to hug each other. That might have to change.

PK: In the Netherlands the picture is quite different. Schools, universities and restaurants are closed, but the rest is left up to common sense, so to speak. That works relatively well, although parts of the country have been seriously hit. Ours is a very densely populated, small country with 17 million inhabitants, which at the same time is the second largest exporter of agricultural products worldwide. Corona-casualties, also in absolute numbers, have been much higher in parts of the countryside then in the larger cities. Perhaps not coincidentally, because of bio-industry there has been much less of a Corona "air quality-bonus"in these parts.

In my city Amsterdam, growing numbers of inhabitants, commuters and visitors haven been posing a huge challenge on mobility within limited space, even though the bicycle has attained inner city predominance already. Adding density while coping with relatively limited rush hour peaks has been determining spatial and financial decisions. It is interesting to see how suddenly this peak has gone, now that temporarily teleworking from home has been widely adopted. I am interested to see if there are lessons to be learnt here. Not to measure density in square meters, but density of use. Will we have a different view on density when we are able to continue to flatten the peaks and use our buildings and public space more "decompressed" and effectively, not just cut up and designed for single use?

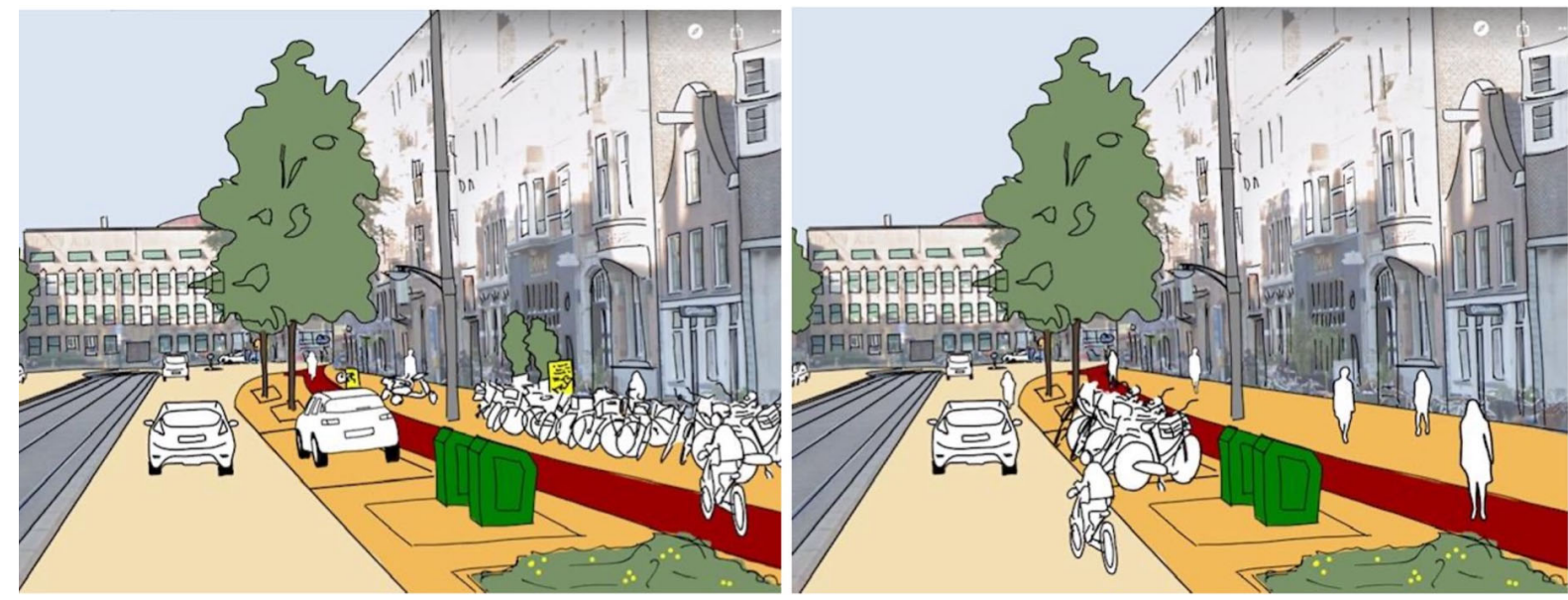

Figure 4. Amsterdam, the temporary measures of public space - undiving public space for social distancing conditions

EO: I would like to point out the importance of agencies and activities in public space. If there are no agencies and activities, no theatres, protests and activists, even welldesigned public spaces are vacant. Tokyo and Kyoto are full of small restaurant, shops and theatres. The image of Japan abroad is that of a super developed, high-tech country while in reality there operate three million small, private companies. Only I\% of companies are exceptionally big. Most of Japanese cultural spaces, such as movie and 
performance theatres, publishers, bookstores and entertainment industries are carried by medium- and small-sized companies.

The Japanese government has decided to introduce the Coronavirus lockdown at the end of March. One month later, in the end of April they decided to provide maximum 2,000,000 JPY (I 880 USD) subsidies for SMEs and maximum I,000,000 JPY for small business owners. Many economists predict that without such subsidies businesses such as bookstores and entertainment companies will not survive a month, or two. I think that in 3-4 months most of cultural activities in Japan might disappear. The same situation is with other urban activities, citizen groups, activists, protestors involved in demonstrations, assemblies, food supplies. During the lockdown they are running out of budgets, losing skills, knowledges and networks that mobilize members in public spaces. Without such agencies, skills and activities, discussion on space design becomes meaningless. That is the main point of the only sociologist in this group.

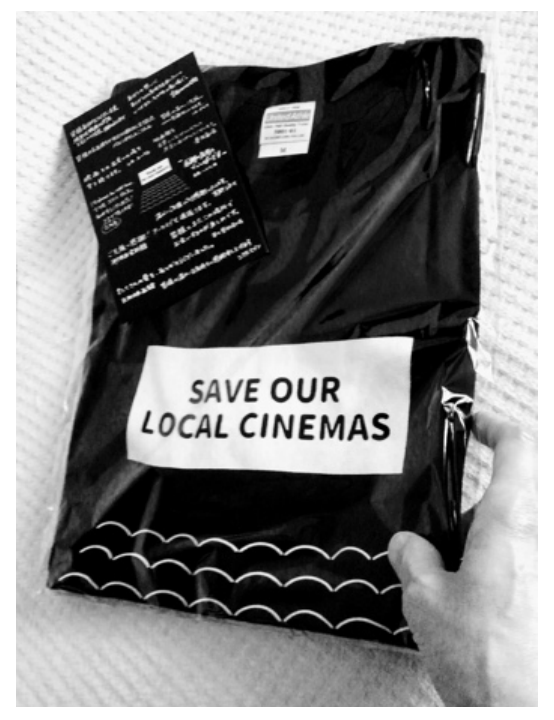

Figure 5. "SAVE OUR LOCAL CINEMAS" T-shirt has arrived. Hot messages from movie theater people. Cine Libre Kobe, Motomachi Movie Theater. Thank you. (from a tweeter feed of Kuri@torso009 on II May 2020)

DR: Exposed to a single, albeit fuzzy and even questionable threat, the World responded in an endless number of ways. That is consistent with my research into diversity of urban cultures: while Coronavirus stands "nicely" next to other globalizing forces, human responses to it were as diverse as we are.

While many talk about "return to normal", it is easy to forget that the pre-Coronavirus reality for majority on this planet was below humanely acceptable conditions. Shouldn't the way out of this emergency be a way forward, not a way back(wards)? That is not a rhetorical question. As in Lefebvre's right to the city, it "is like a cry and a demand. It can only be formulated as a transformed and renewed right to urban life". While questioning the return to "normality" might be dismissed as unrealistic, we do need new realism grounded in environmental and cultural sustainability, and to expose the "return" itself as unrealistic and totally irresponsible. There should be no cost-benefit analysis of health and life, including social life. To achieve that - cities need new kind of politics.

These times make us realise how hard is to formulate new, relevant questions. Those questions need to be based on the idea(I)s of humanism, democracy, urbanity, right to the city, solidarity, conviviality. The locked-down cities offer many manifestations of 
these ideals - lived, exercised, practised. From that one can learn a lot, but only after the first lesson - that we should not return to Debordean Spectacle in which "the globalization of the false was also the falsification of the globe".

SS: I've stayed indoor for more than a month, rarely leaving the house. I see that public spaces and "others" are now perceived as "diseased"; fear has revealed and intensified camouflaged biases. My observation focuses on two contestations in 'digital public space'. One is the Geopolitical contestations, the big picture of China vs. the West blame game. That is affecting the geopolitics and economic reopening that we are discussing. This urban ethno-centric contestation manifested in a video clip of a racially motivated attack on two international students in Melbourne's CBD. Attacked as "Chinese", they are Malaysian and Singaporean. The second contestation manifests itself in informal urbanism exacerbating in inequity in Thailand. The 'new' urban poor, part of the pre-Covid-19 socially mobile class, are queueing for food and money donation from mostly private benefactors. This sustains the beneficial aspect of informal urbanism, the role that streets played in providing opportunities, now providing strong social support while at the same time in the virtual media exacerbate the work-from-home, middleclass prejudice that people are crowding and spreading the disease.

My position is that, more than ever, we need micro-scaled, human face-to-face experiences of difference in public spaces. That is not a return to the "village square", but rather a 'retreat' from the antagonistic global digital public realm to city's tangible spaces.

\section{DISCUSSION}

SC: Let me begin with just one theme that I have experienced, that l'm sure others feel too: My daily life has gradually blurred morning and evening, day and night, weekend and weekday. That is related to Pieter's point about scheduling of the city. [...] It seems to me that the temporality of the city becomes super interesting and important to connect to the issue of managing density. Many studies have been done on breaking up the 9 to 5 commuter logic of the city. [...] There are all kinds of larger trends heading into that direction, such as the four-day working week, the rise of cyber-physical infrastructures, the robotisation of labour. What struck me in my own daily life, but also listening to this discussion, is that temporality, alongside the obvious spatiality of the city needs to be considered. An old theme, how spaces are occupied in time, should be reactivated in this new framework.

DR: We can speak about long rhythms, short rhythms and singular moments which highlight certain issues. Therefore - temporality of urban life in the times of Coronavirus. This moment has triggered certain sensibilities and certain possibilities.

SC: The city is getting used in different ways. Those are not necessarily new practices, but they are certainly being retrofitted with interesting technological developments. This is a practice issue that needs larger frameworks. I agree with you, we are inside a different temporality. We are being forced to experience different kinds of temporality. At the moment, we feel a larger sensitivity to the question of time, and how this might be experienced will vary radically depending on which density you occupy. 
PK: I agree with Stephen. It also struck me what Alenka said about adapted behavior in view of local culture. Kuma-san also wrote about that. Practically and technically a lot of things are still functioning, sometimes even more effectively so. Perhaps we could organize a spread-out society which functions while keeping to distance rules. But there is also a "social craving". The opening of the lock-down will not just be for economic reasons, as the very meaning of social life and face-to-face urban culture is the key issue.

AF: I would like to add another point, based on a lot of time spent on Zoom, giving online lectures, corresponding with students and urban designers, I am afraid that my students are having better results than in normal life. Everyone attends, everyone is on Zoom. They have never been so good. Someone may tell us, you have done so good, why would university not turn online. But, I really like working with students, learning by doing things together, making things, having fieldwork. How to do that in the time of distancing? We follow the rules, but we must be concerned with that does to us.

My second point is that of globalization. Knowing that we will not have trips to unknown places, experience new cultures, encounter different faces, discover other typologies and so on - do we only need to think how to stay safe?

My last point is based on an observation that, in my country, some of the business owner prefer to keep them closed not because of Coronavirus, but for economic reasons. Full compliance with the rules of distancing, cleaning, sitting, limiting numbers etc. damages their income, and they prefer to close. Those are significant cultural changes. Which types of activities are going to survive? How will the use of open spaces react to that?

EO: The social distancing might advance centralization of capital and downfall of small companies, as predicted by Karl Marx in $19^{\text {th }}$ century. Social distancing requires tools or platforms for communication, such as Amazon, Google, Facebook. That could cause centralization. For instance, in Japan bookstores flourish. About two times per capita comparing to UK, and four times to the US. Because of the lockdown there are no visitors and customers, bookstores will have to close. Only Amazon and the likes will be able to supply books and food. That could result in domination of big suppliers. Direct face-to-face communication and urban density guarantee direct communication and cultural diversity. If we let the current trend to proceed, diversity might be provided only via Netflix and Amazon. All that together would critically deprive smaller groups of people.

PK: That is an interesting point that brings us back to the question of density. One could say that a society which Oguma-san describes could be the ultimate result, the nightmare resulting from this crisis. This might be less dramatic in low-density non-urban areas. But it could be catastrophic to urban density conditions. Density should not just be measured in numbers, but as density of behavior and cultural patterns - what ultimately makes the society.

DR: In the period 20I I-I4 we had a major research project Measuring the nonMeasurable, which has dealt with dialectics between urban density and intensity, also asking - the density of what? That is in the spirit of Georg Steiner, who described that the density of discourse made Greek polis an epitome of the public. 
Up to this moment, our discussions pointed at human nature, at the need for what JeanLuc Nancy formulated as "being with". That is not Heideggerian "being", living in an isolated hut to fully be (human). We are like chemical elements; we need another human being to create a "molecule". That is our precious, defining social capacity and need. As Pieter has put it, social craving. Prisoners get additionally punished by isolation, by solitary confinement. These days we are all becoming Zoombies. Zoom and Webex cannot replace, they only reduce reality. From citizens, we have already been reduced to consumers; now, we all became users. SC mentioned the example of Singapore, where Coronavirus dented the famed efficiency and cleanness by exposing hidden reality, the existence of an invisible underclass.

SC: That reflects what Sidh mentioned. The issue of class gets revealed in the time of crisis.

I am also interested in Alenka's report about studio teaching. I am fond of the same kind of things. I also love bookshops, cafés, markets, but I am skeptical about nostalgia that we might attach to that kind of sociality. I would rather be in Tokyo talking together in a nice restaurant, but this - this virtual, zoom-enabled - kind of sociality is only possible at this moment because of the particular condition and technological mediation. Perhaps there is a new kind of sociality taking shape. I agree with Darko this is a "being with", the relational issue. Density is always quantitative and qualitative. This is a technologically enabled social meeting. This interface diminishes it in some way, but enhances in another way. I do take the point about the dark under side of the cause. There has to be some way in which the digital media becomes a commons. Where is the governance system that would allow the commons of the web to emerge? I agree with you, but I am skeptical about nostalgia for old forms of sociality.

DR: It is not either-or, it is both. There was never a city without technology, of course. This idea about governance is of critical, strategic importance, getting it straight across scales. Only, to me, the idea of global governance and government is always dangerous.

SS: Continuing on Stephen's point about social media as public space, or commons. This is one of major challenges as this type of commons seems to be making things worse, not better when we return to real space. I also want to raise the question of 'privilege', the position we are in when discussing and talking about all of this, whether it is compromising, devaluing the real space if this becomes the 'new normal'. I am sure that tech companies have plans in place to make these tools function better, taking us further away from real physical spaces, tangible social interactions, especially with people who are different from us.

In Singapore, where the story of the First World was, in a month, followed by the story of the Third World situation. Those two worlds seem to be totally segregated, with no links between them. Global audiences became aware through this new interfacing. SC: They were physically separated, in tangible physical spaces. Digital media, such as Tiktok, allowed us a glimpse into those realities.

DB: Environmental issues have not been mentioned yet. We are looking at this Coronavirus issue from an anthropocentric perspective, how all this affects human health and human well-being. But the lockdown, stopping of many human activities 
(gatherings, traffics, travels) has significantly reduced our environmental impact. For instance, Bangkok "normally" has a tremendous problem with air pollution, but during the lockdown people can breath clean air again. To me, the question is what will happen when the lockdown gets eased and human activities resume? Should we allow ourselves to return to that unacceptable "normal", or seek ways for not going to the same place?

EO: I don't intend to stick to nostalgia, but I want to make a point related to the character of interaction in communication with social distancing and in digital media. Being out in, for example, Central Park will cause coincidental interactions. If we visit the Park, we will meet come across unexpected persons, people of different social class. If we were to interact in digital media, our communication is limited to the same class, same level of education. That causes the decline of diversity, and polarization.

Researchers of social media claim that they follow the Biblical Law of Mathew, with rich becoming richer, and poor staying poor. [...]Marshall McLuhan, pointed out that printed media enhance only one single sense of vision. In this Webex meeting, we can see and listen, but we cannot smell each other. Of our five senses, digital media engage only two. I think McLuhan suggested that such kind of limitation in communication contributes to the raise of nationalism, homogeneity and centralization.

DR: Referring back to the Nancean "being with" and reduction to only two senses, all of us here as well as our students in their "cells" get reduced, flattened to only one task at the time. While such reductionism might increase "useful" execution of certain tasks, it does diminish our humanity.

\section{Roundtable session 2, I May 2020}

Antonella Bruzzesse AB, Beatriz Maturana Cossio BMS, Ana Medina AM, Darko Radović DR

David Sim DS, Saline Verhoeven SV, Davisi Boontharm DB, Chair

\section{INPUTS}

DB: I am privileged to be locked down in a beautiful city, but that beauty is now reduced to that of space, to pleasure for eyes. That beauty cannot compensate for an awareness that people suffer, with no income, no spaces that feel safe.

“Think Globally act locally". The pandemic has stopped global movement and activities. It limited us to basic needs, depriving us of social life. The lockdown also heightens everybody's responsibility towards others. One of direct consequences is the collateral dramatic reduction of emissions. In congested and polluted cities like Bangkok the lockdown has brought back the sidewalks, clean air, smooth traffic. However, the most vulnerable people whose lives depend on streets are paying huge price. It shows that something is wrong in the system we are living in.

What if we don't stay limited to anthropocentric perspective. I ask: is it possible to "restart" towards genuine triple bottom line? The release of the lockdown is coming, but we shouldn't go back to "business as usual". We should learn from this crisis. Can elements of the lockdown become new "normal", giving priority to environmental quality, social equity and different economy? 
AB: I Live Milan. Lombardy is one of the regions worse hit by Coronavirus. The mantra "stay at home" opens the question "what is home?". Studying public housing in Milan, I investigated what l've called "sequences of domestic spaces". Not only the apartment but a series of different spaces are part of our experience of inhabiting our idea of home: public and collective spaces that somehow makes the city. Otherwise, we have gated communities with well-equipped and introverted houses unable to create spaces of exchange and urbanity or, at the opposite, a series of small apartments unable to fully respond to the needs of the people. The opposite of a livable city. This crisis has reduced the idea of home to private, familiar spaces. This concerns our understanding of living space, creating an opposition where interior, home is private and safe, and outdoor, public is dangerous. A kind of mistrust in public space has emerged, while the infections actually happen mostly in closed and private homes. In order to make public spaces work again, we have to dismantle such mistrust and rebuild the meaning of public space, to bring it back into our understanding of home, inhabitation and good living. We are not facing an easy future. On one side there is a strong push to go back, as if forgetting COVID was possible; on the other side is the push towards privatization, gated houses as supposedly safer. In the middle is a challenge of new normality, new ordinary, public spaces with distanced people, different scales of intervention, even in time. We need to go back to public space, with stronger attention and different proxemics. For Ugo La Pietra "living is feeling at home everywhere". In order to build the new ordinary, we need to feel safe both at home and in public space.

BCM: In Chile, before the pandemic, five months of a politically motivated crisis was played out in public space. On October 18, 2019, unprecedented citizen violence exploded with widespread looting, arson and vandalism destroying public buildings, urban facilities and infrastructure. Formerly a good example of integrated living, by March 2020 the centre was destroyed by this protest and renamed Ground Zero. Public pride was transformed into public fear and residents fled. The self-induced recession that followed was suspended on March 18 by COVID 19. It sounds terrible, but the pandemic saved the city. The destruction is being repaired and the threat to citizens is in quarantine. We can hear the birds not the riots, smell the air not the arson.

I am interested in ethics of public space, as much as in its physical changes in any crisis. How a functioning and economically growing capital city (carbon neutral by 2040) can evolve into a public disorder of "protest" that can destroy the infrastructure and trust of its public spaces that can only be stopped by a public health crisis.

AM: People make cities and public space is about time. We are confined indoors (those who are lucky to have a house) while the city is being attacked by an invisible monster. Now, we only see empty public spaces. Changes considered impossible became real: from cultural buildings transformed into hospitals to anti-riot water-cannons disinfecting streets. Social distancing makes me think of three themes: (I) surveillance was with us for years, but now it inside us; (2) informal local activism gets redefined; (3) how public space will be in informal cities, which is the normality for millions?

DS: Urban life is defined by time and place. Paradoxically as the world has slowed down, we seem to have more time, we have become time rich. The world gets smaller and we more mindful. Simple experiences have gained more significance: eating, going for a walk, a 
bit of sunshine on your face, wind on your skin. Sensory moments became more significant, as we have time to notice them.

I am concerned about human scale. Things like a window suddenly become more significant. A balcony. A front garden. Would you like to negotiate space with others in an elevator, or take staircase so that you can manage the contact? In this crisis, different urban forms make our lives easier, or more difficult. The buffer spaces (windows, doors, balconies, front gardens), which seem like boundaries, are connecting us, allowing us to be together. Like a mask that allows us to be closer, yet separate. We can still socialize, while keeping physical distance. The softness of architecture lets people connect to the world.

SV: In Amsterdam we have "intelligent lockdown". People are advised (not forced) to stay at home as much as possible. In discussions about limited public space, infrastructure, cars, economy, money-related issues usually win from adding green space. But in the times of Coronavirus green spaces are amongst the basic needs. For me, healthy cities are those that combine ecological, physical and mental health.

People walk. Walking eases stress. Walking is a nice way to uplift your spirits and to reflect. Dispersed accessibility of enough green space helps. In the Netherlands, people were heading to popular nature parks and regions in such numbers that they had to be closed, to avoid overcrowding.

Space can be found. Trying to work from home, we don't commute; we do not need to travel much. Travel is commonly considered as essential. How to turn such thinking around? Can we rethink car-oriented mobility? Giving space to humans. Healthy economy needs healthy population.

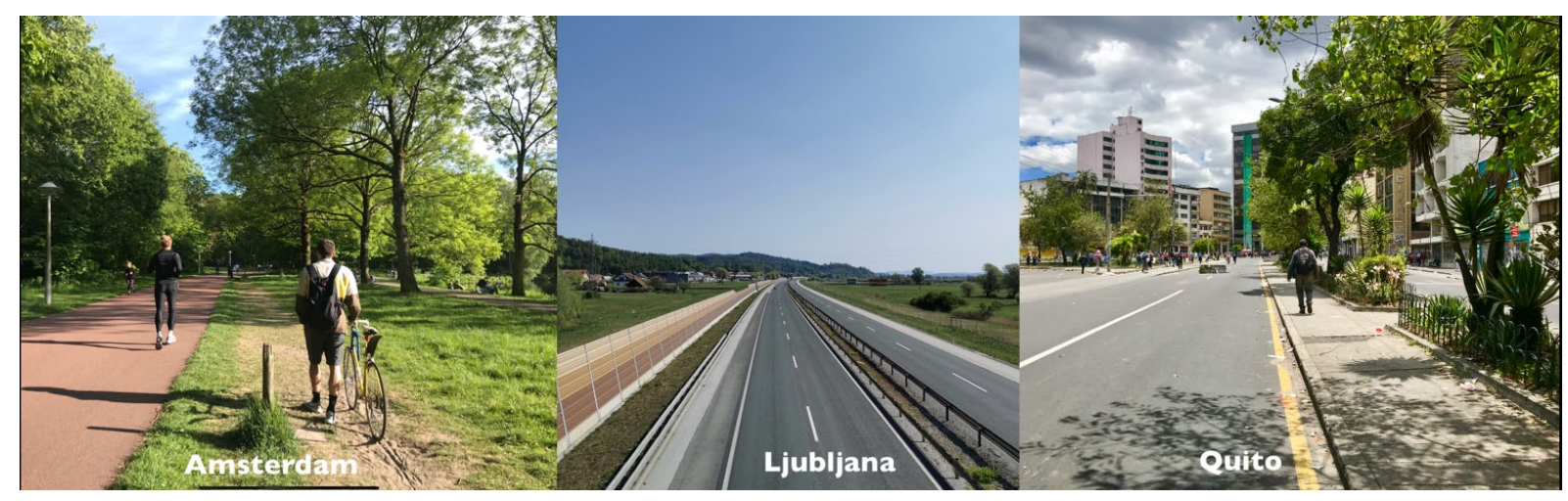

Figure 6. Adding room to walk in a park in Amsterdam, the empty highway in Ljubljana and clam street in Quito

\section{DISCUSSION}

DR: Many discussions address normality. If we agree that in these times of crisis, which is not going to end abruptly or fast, the dominant, so-called "free" market economy doesn't work, a question to ask is - what kind of economy can work? The return to economy which does not work makes no sense.

I also want to highlight the importance of politics. Involvement of medical experts in dealing with pandemic provides the sense of confidence. I believe them. But now, economists are getting back as key advisors to politicians, and - I do not believe these advocates of a particular school of economy. Cities need generalist experts, capable to 
deal with the totality of the city. Of course, that is complex. Balcony makes full sense only when there is somebody, hopefully someone significant to you, down in the street.

DS: In Sweden the crisis is non-political. This situation is totally run by the experts. The Prime Minister stood back. The schools remained open, as closing them was an emotional question. Across the EU the trust in government varies. Should we talk about the software, governance, trust and control, or about something physical, the fabric of the city?

DR: For me, in Lefebvrian way, each city is spatial projection of a concrete society. When talking about society we already speak about "hardware". Every city looks precisely like the society producing it.

DS: But suburban Netherlands looks like suburban America. Detached houses and cars seem safe, but they are separate from everything else. In urban environments we are better connected, we survive because we know our neighbours, we are closer to things, we can better organise our lives on foot. We don't have to have a car. Which environment performs best in the time of crisis?

DR: To that, I would only add - "where?".

BCM: Globalization is one of my themes. The virus is shared globally, but response varies according to the social, economic and political conditions of each country. Chile has an enviable record in its approach to COVID 19. The pandemic has revealed the question of self-reliance and the government's ability to coordinate and commandeer the goods, services and resources of the public, private and civil society sectors. The world's dependence on China for primary materials, technology and products, including medical, has shifted thinking in many countries.

DS: In Japan you do not wear the mask to protect yourself, but to protect others. It may be uncomfortable for me, but it protects you.

SV: I want to discuss that in terms broader than masks. City space can generate or stimulate care for others. In Amsterdam I notice that, when spaces get crowded, people give room to others. Providing room for everybody is an issue for urban design.

DR: Wearing the mask, or keeping distance are expressions of urbanity. I disagree with politicians stepping back. They should represent us, as an executive arm of our will. They should listen to experts, make us informed, take and let us take responsibility.

Responsibility distinguishes citizens from consumers.

AB: I live in the region where more than 12,000 have died (now I5.000!). Every local situation is different and differently influences our questions and issues. What can be in common is that as our space of living has been reduced (home), our attention increased, for example I became more aware of the people I meet and the places I lived in; our understanding of needs towards public spaces somehow changed: I need green spaces but for a dispersed use to keep safe distances; we need to go back to a more complete idea of public spaces including our bodies, or the unexpected: digital media (as this one) it is not enough. So what to do? What the public administrator have to do? 
DS: There is a question of responsibility. It is not about giving up responsibility, it is about leaving it is up to the individuals to use their common sense instead of applying blanket rules. It is about decentralizing the decision making, applying common sense to allow society to work, to be able to live even 2-3 years in the situation of lockdown.

AM: Following Antonella point, Ecuador doesn't have a government capable to deal with disasters. Everything is down to the local governments. The two biggest cities, Quito and Guayaquil, are very different. Guayaquil is hot and humid, highly dense. People depend on air-conditioning. Spending precious time outdoors became impossible. Quito depends on daily informal economy. Neither public spaces are democratic, but time is.

BMC: Continuing with what Ana and Darko said about capitalist neoliberal politics, I agree, the city is political and economic. For forty years neoliberal politics led Chile to a different place from where it was before. However, this government has dealt with Coronavirus in a very technical way, which works. Chile is 4000 kilometers long and highly centralized which appears to be a problem. Santiago has one third of the country's population. In our COVID 19 response, centralization has provided a coordination of the public health services, infrastructure and equipment that are planned and delivered in this circumstance. Country without economy will starve people to death. ... Politics, economics and the city are never straightforward.

DB: In the previous session, SS mentioned another type of conflicts, the search for scapegoats. In some countries politicians want to sue the Chinese government. Xenophobia gets expressed in public. In Melbourne, two Chinese-looking students were attacked. So, yes, we are aware of each other in public space, but let's not forget that those spaces are conflictual.

DR: Globalisation is an elephant in the room. It is not only that difference exists; we are entitled to our differences. In the times of crises, the likely scapegoats are precisely those who don't look like me, like majority. The loss of diversity and cultural difference to this crisis would be terrible. Protecting the right to be different is a civilisation imperative.

DS: We have different politics in the background, which is natural. We became aware that we need people of lower skills more than ever before. The crisis made us see them and appreciate their contribution. I want to bring the conversation back towards physical.

SV: People and circumstances are different. As Antonella stressed, the city is our home, so we should be aware that everybody needs good life. Spaces have to be flexible to accommodate others. Public space is part of our homes, that is important.

AB: Our discussion is becoming clear. It not only about space, but about interdependences and relationships between people. My possibility and way to stay in public depends also on the behavior of others. We are enlightening a banal but important issue - the significance of interdependence. 
AM: Using public space only "when needed" is a frightening issue. It takes long to democratize space, which now gets subjected to increased control. What would be the ways other than government surveillance of public space? Some kind of resilience, dissidence, resistance? Bottom-up provision for the needs of people, local dynamic, extra small scale?

DR: Availability of public space at all time is needed, to which Kuma-san referred by invoking Giambattista Nolli's Map. That is part of the right to the city. When I say politics, I mean even that of the shared corridor, which Antonella mentioned earlier. As soon as we encounter other people, we are negotiating space. All relationships are political, the Nancean "being with". Public spaces provide opportunities to meet even those whom we dislike. It makes us aware of each other, form positions about each other, about difference itself. Thinking about politics is not primarily about politicians, but about being human.

BMC: The quarantine helps us reflect upon consumer society. I was lucky to live in a cultural precinct with art galleries, shopping, theaters, cafés, music, restaurants with tables on the footpaths, where going out and using public space to "see and be seen"which also meant consuming - was essential. The pandemic has made many realize that we do not need much to live well and I wonder whether there is a level of fetishism about intense "café culture" and public space.

\section{OUTPUTS or - INSTEAD OF CONCLUSIONS}

The following words and phrases kept on reappearing and stayed lingering on, after the discussions were over.

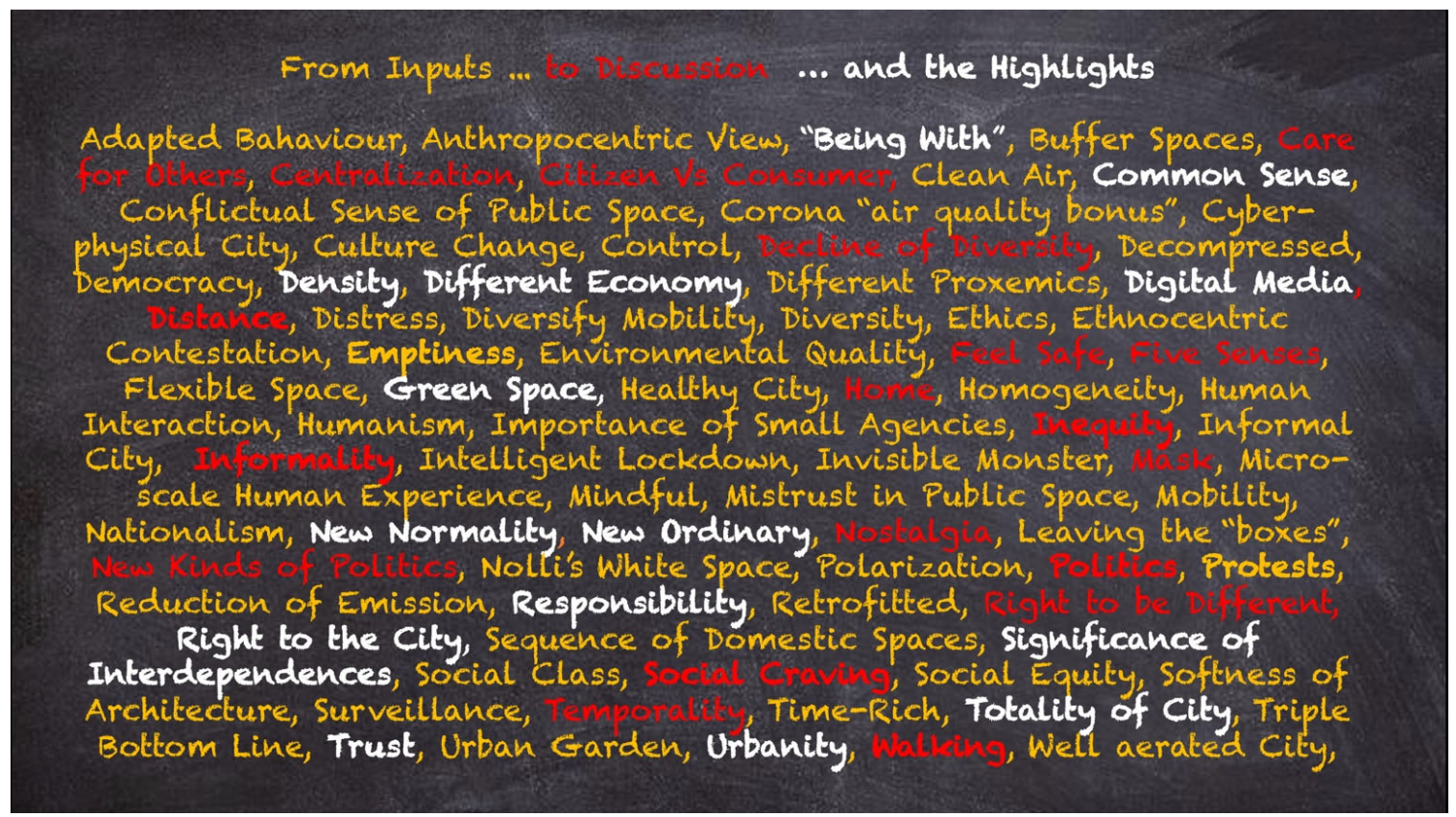

Figure 7. Blackboard of keywords raised from the two sessions of round tables in alphabetic order (curated by Davisi Boontharm) 